\title{
PENENTUAN KOEFISIEN ABSORBSI DAN IMPEDANSI MATERIAL AKUSTIK RESONATOR PANEL KAYU LAPIS (PLYWOOD) BERLUBANG DENGAN MENGGUNAKAN METODE TABUNG
}

\author{
Sonya Yuliantika, Elvaswer \\ Laboratorium Fisika Material, Jurusan Fisika FMIPA Universitas Andalas \\ Kampus Unand, Limau Manis, Padang, 25163 \\ email :sonyayuliantika@gmail.com
}

\begin{abstract}
ABSTRAK
Penelitian ini untuk menentukan nilai koefisien absorbsi bunyi dan impedansi akustik dengan menggunakan metode tabung impedansi. Sampel yang digunakan yaitu material beton dan kayu lapis. Rentang frekuensi yang digunakan yaitu $500 \mathrm{~Hz}, 1000 \mathrm{~Hz}, 2000 \mathrm{~Hz}, 4000 \mathrm{~Hz}$ dan $8000 \mathrm{~Hz}$. Hasil menunjukkan bahwa koefisien absorbsi bunyi beton 0,25 pada frekuensi $2000 \mathrm{~Hz}$. Setelah dilapisi resonator panel kayu lapis meningkat menjadi 0,51. Beton yang dilapisi resonator panel kayu lapis berlubang didapatkan koefisien absorbsi bunyi paling tinggi yaitu 0,61. Impedansi akustik paling tinggi pada beton dilapisi resonator panel kayu lapis berlubang yaitu sebesar 0,97$i 0,05$.
\end{abstract}

Kata Kunci : koefisien absorbsi bunyi, impedansi akustik, beton, kayu lapis dan resonator berlubang

\section{PENDAHULUAN}

Rancangan arsitektur bangunan pada umumnya kurang memperhatikan pengendalian bunyi di dalam ruangan. Dinding bangunan yang digunakan dominan terdiri dari batu bata yang diplester atau disebut dengan beton. Penghalang yang keras dan tegar seperti beton mengakibatkan sebahagian besar bunyi dipantulkan. Bunyi dalam ruang yang dipantulkan jika tidak dikendalikan akan menjadi sumber kebisingan.

Bunyi adalah gelombang mekanik elastik longitudinal yang berjalan. Gelombang longitudinal terjadi karena perapatan dan peregangan dalam medium cair, padat atau gas. Gelombang dihasilkan ketika sebuah benda digetarkan dan terjadi getaran molekul yang berlangsung sepanjang arah penjalaran gelombang (Tipler, 1991).

Kebisingan merupakan penyelubungan sumber bunyi yang menyebabkan sulit mendengar sumber bunyi dengan jelas. Penyelubungan biasanya terjadi dalam ruangan dengan rancangan akustik yang tidak memadai. Penyelubungan yang terjadi pada suatu ruangan dapat dikurangi dengan menggunakan bahan penyerap bunyi. Bahan tersebut dalam suatu bangunan biasanya berperan sebagai panel-panel akustik yang dipasang pada dinding pemisah dan plafon (Doelle, 1986).

Material penyerap bunyi adalah material yang dapat menyerap energi bunyi yang datang ketika gelombang bunyi menumbuk material tersebut. Bunyi akan menumbuk partikelpartikel di dalam material, kemudian oleh partikel dipantulkan ke partikel lain, sehingga bunyi terkurung di dalam material. Material penyerap bunyi terdiri dari material berpori, material penyerap panel dan material resonator rongga (Lewis dan Douglas, 1993).

Sumber kebisingan diantaranya adalah peralatan yang dimekanisasi. Komponenkomponen sistem mekanisasi misalnya pemanas, kipas angin, kompresor dan komputer. Alat-alat rumah tangga juga merupakan sumber kebisingan seperti pembersih vakum (vacum cleaner), pencuci piring, penghancur sampah dan televisi. 
Absorbsi bunyi yaitu penyerapan energi bunyi dari suatu sumber bunyi dengan menggunakan material penyerap bunyi misalnya kayu lapis, ubin dan panel berlubang. Kualitas dari material penyerap bunyi ditunjukkan dengan koefisien absorbsi bunyi, dimana semakin tinggi koefisien absorbsi bunyi semakin besar bunyi yang diserap dan semakin rendah koefisien absorbsi bunyi semakin kecil bunyi yang diserap. Dilaporkan kayu lapis sebagai penyerap frekuensi bunyi rendah yang efisien. Bahan ini banyak digunakan dalam rancang bangun ruangan. Koefisien absorbsi bunyi kayu lapis yaitu 0,45 pada frekuensi $100 \mathrm{~Hz}$ dengan menggunakan metode revebrasi sabin (Doelle, 1986).

Kayu lapis tanpa celah memiliki nilai koefisien absorbsi bunyi lebih kecil dari pada kayu lapis bercelah. Dilaporkan bahwa nilai koefisien absorbsi bunyi kayu lapis tanpa celah yaitu 0,39 pada frekuensi $1000 \mathrm{~Hz}$, sedangkan dengan celah meningkat menjadi 0,51 pada frekuensi $1000 \mathrm{~Hz}$. Metode yang digunakan metode tabung impedansi. Kayu lapis bercelah dengan diameter $2 \mathrm{~mm}$, bermerek As yang diproduksi oleh PT. Kampari Wood Riau (Oktaviani, 2013).

Beton serat tandan kosong kelapa sawit memiliki nilai koefisien absorbsi bunyi yang kecil. Nilai koefisien absorbsi bunyi pada beton berkisar antara 0,01 sampai dengan 0,05 dengan rentang frekuensi $100 \mathrm{~Hz}$ sampai dengan $5000 \mathrm{~Hz}$ (Gurning, 2013).

Bahan akustik resonator panel berlubang yaitu panel yang berbentuk lubang-lubang yang berfungsi sebagai deretan resonator rongga, lubang yang dimaksud yaitu berbentuk lingkaran, bila panel berlubang dipilih dengan tepat akan menambah efisiensi absorbsi bunyi dan akan memperlebar daerah frekuensi bunyi dimana penyerapannya cukup besar. Resonator panel baja berlubang dapat meningkatkan koefisien absorbsi bunyi dibandingkan dengan resonator panel baja tanpa lubang. Koefisien absorbsi bunyi resonator panel baja berlubang yaitu 0,4 pada frekuensi $2000 \mathrm{~Hz}$ dan koefisien absorbsi bunyi resonator panel baja tanpa lubang yaitu 0,2 pada frekuensi $2000 \mathrm{~Hz}$ (Doelle, 1986).

Metode untuk menentukan koefisien absorbsi bunyi antara lain metode tabung impedansi dan metode revebrasi Sabin. Metode tabung impedansi untuk mengukur koefisien absorbsi bunyi yang memerlukan material akustik dalam jumlah yang sedikit, praktis dan sederhana. Metode tabung impedansi sesuai untuk kajian-kajian teori. Metode revebrasi Sabin memerlukan material yang banyak karena seluruh ruang dilapisi dengan material akustik.

Standarisasi nilai koefisien absorbsi bunyi pada suatu material sangat penting untuk penerapan material akustik, berdasarkan standarisasi tersebut maka dapat dirancang suatu bangunan akustik dengan memilih bahan-bahan yang sesuai dalam perancangannya. Penelitian ini akan melihat perubahan koefisien absorbsi bunyi dan impedansi akustik dari bahan beton, beton dilapisi resonator panel kayu lapis dan beton dilapisi resonator panel kayu lapis berlubang dengan menggunakan kayu lapis bermerek As. Tujuan dari penelitian ini yaitu menentukan karakteristik koefisien absorbsi bunyi resonator panel kayu lapis berlubang yang dilapisi pada beton. Manfaat penelitian ini yaitu mengurangi kebisingan, meningkatkan kenyamanan dan kesehatan. Metode yang digunakan pada penelitian ini yaitu metode tabung impedansi. Metode ini menentukan koefisien absorbsi bunyi dengan menghitung perbandingan amplitudo tekanan maksimum dengan amplitudo tekanan minimumnya. Perbandingan amplitudo tekanan ini dinamakan rasio gelombang tegak (Standing Wave Ratio). Secara matematis nilai rasio gelombang tegak dapat dinyatakan pada Persamaan 1 (Beranek, 1949).

$$
S W R=\frac{(A+B)}{(A-B)}
$$


Dengan $(A+B)$ yaitu amplitudo tekanan maksimum, $(A-B)$ yaitu amplitudo tekanan minimum dan $S W E^{\circ}$ yaitu rasio gelombang tegak. Koefisien absorbsi bunyi $(\alpha)$ dapat ditentukan dari Persamaan 2.

$$
\alpha=1-\left(\frac{g W E-1}{G W R-1}\right)^{2}
$$

Impedansi akustik dapat ditentukan dengan menggunakan persamaan 3.

$$
z_{z}=\operatorname{coth}\left(\psi_{1}+\psi_{2}\right) p c
$$

Dengan $Z_{z}$ adalah impedansi akustik (dyne.s $\left./ \mathrm{cm}^{5}\right), \rho$ adalah kerapatan di udara, c adalah kecepatan bunyi di udara. Untuk dapat menentukan impedansi akustik terlebih dahulu harus ditentukan nilai $\psi_{1}$ dan $\psi_{2}$ dapat dinyatakan pada persamaan 4 dan Persamaan 5 (Beranek, 1949).

$$
\begin{aligned}
& \psi_{1}=\operatorname{coth}^{-1}\left(\log _{10}(\mathrm{SWR} / 20)\right) \\
& \psi_{2}=\pi\left(\frac{1}{2}-\frac{\mathrm{d}}{\mathrm{a}_{\mathrm{g}}}\right)
\end{aligned}
$$

$\psi_{1}, \psi_{2}$ adalah bilangan kompleks, $d_{1}$ yaitu jarak amplitudo minimum pertama dari sampel $(\mathrm{cm})$ dan $d_{2}$ adalah jarak amplitudo minimum kedua dari sampel $(\mathrm{cm})$

\section{METODE}

\subsection{Pembuatan beton, beton dilapisi resonator panel kayu lapis dan beton dilapisi resonator panel kayu lapis berlubang.}

Beton dibuat dengan komposisi 200 gr pasir, 100 gr semen, 100 gr kerikil dan $500 \mathrm{~mL}$ air semuanya diaduk sampai homogen kemudian dimasukan ke dalam cetakan, setelah 1 minggu beton dilepas dari cetakannya. Beton dengan perlakuan dilapisi resonator panel kayu lapis berlubang dengan diameter $0,3 \mathrm{~cm}$ dan ukuran lubang yang digunakan adalah $0,1 \mathrm{~cm}$. Resonator panel kayu lapis berlubang memiliki empat bagian lubang dari dalam ke luar yaitu dua belas lubang, dua puluh lima lubang, tiga puluh lubang dan enam puluh delapan lubang. Diameter kayu lapis yang digunakan adalah $8 \mathrm{~cm}$ dengan ketebalan 0,2 $\mathrm{cm}$ sedangkan diameter beton yang digunakan adalah $8 \mathrm{~cm}$ dengan ketebalan $2 \mathrm{~cm}$.

\subsection{Pengujian menggunakan Tabung Impedansi}

Pengujian akustik untuk mengetahui kemampuan resonator panel kayu lapis berlubang dalam menyerap bunyi, dilakukan dengan menggunakan tabung impedansi. Tabung impedansi dilengkapi dengan beberapa alat antara lain: mikrofon, amplifier, catu daya, osiloskop, sinyal generator, loudspeaker, skala dan sampel seperti diperlihatkan pada Gambar 1.

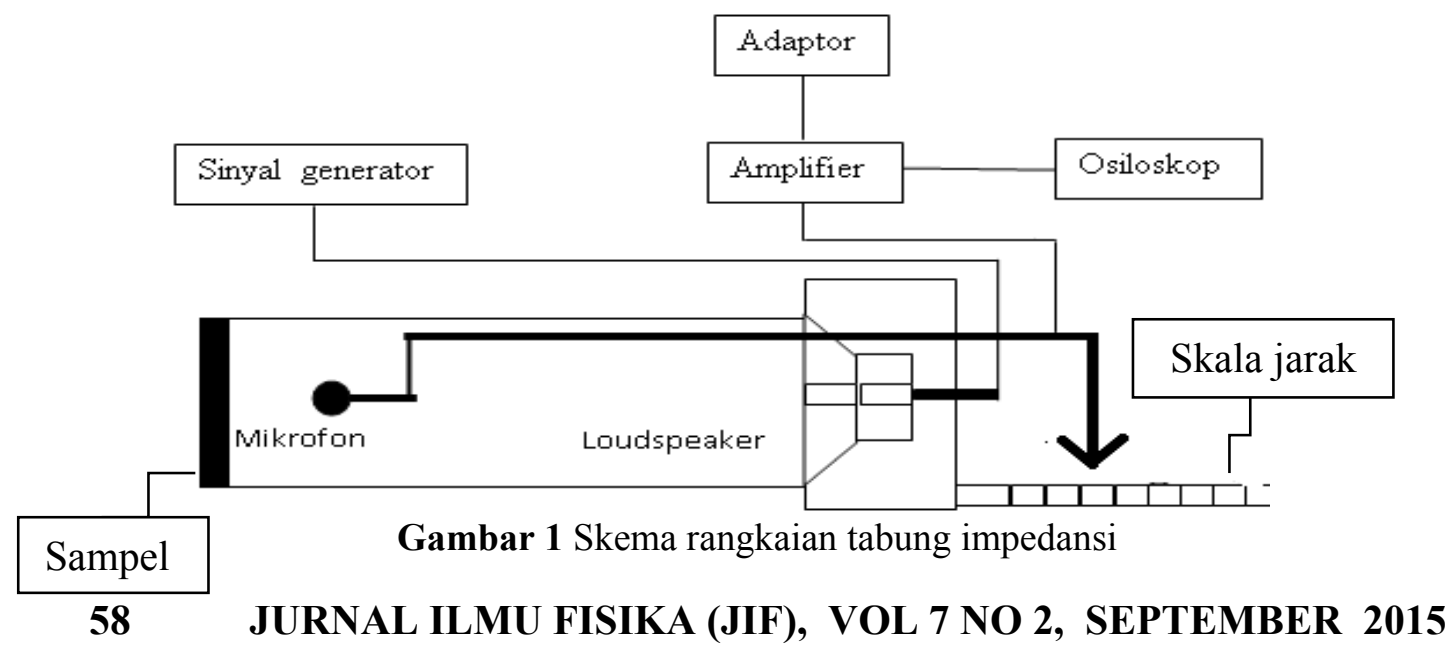


Loudspeaker dihubungkan dengan generator sebagai penghasil bunyi. Diletakan ujung tabung loudspeaker dan ujung tabung yang lainnya adalah sampel. Mikrofon diletakkan ditengah-tengah diameter tabung ke arah sampel material akustik. Mikrofon diletakkan diujung sebuah kawat sehingga dapat digeser untuk menentukan amplitudo tekanan maksimum dan amplitudo tekanan minimum.

Mikrofon diperkuat dengan amplifier dan dihubungkan ke osiloskop seterusnya dilakukan pengukuran gelombang. Gelombang yang diukur adalah amplitudo tekanan maksimum dan amplitudo tekanan minimum serta jarak amplitudo minimum pertama $\left(d_{1}\right)$ dan jarak dari amplitudo minimum kedua $\left(d_{2}\right)$ dari sampel. Frekuensi yang digunakan dalam penelitian ini adalah frekuensi oktaf-band yaitu $500 \mathrm{~Hz}, 1000 \mathrm{~Hz}, 2000 \mathrm{~Hz}, 4000 \mathrm{~Hz}$ dan $8000 \mathrm{~Hz}$ (Doelle, 1986).

\section{HASIL DAN DISKUSI}

\subsection{Hubungan Frekuensi dengan Koefisien Absorbsi Bunyi}

Hasil pengukuran amplitudo tekanan maksimum $(A+B)$ dan amplitudo tekanan minimum $(A-B)$ dapat digunakan untuk menentukan nilai koefisien absorbsi bunyi. Koefisien absorbsi bunyi dihitung dengan menggunakan Persamaan 2. Koefisien absorbsi bunyi seperti diperlihatkan pada Tabel 1 .

Tabel 1 Nilai koefisien absorbsi bunyi material akustik terhadap frekuensi

\begin{tabular}{|c|c|c|c|}
\hline \multirow{2}{*}{$\begin{array}{c}\text { Frekuensi } \\
(\mathrm{Hz})\end{array}$} & \multicolumn{3}{|c|}{ Nilai koefisien absorbsi bunyi $(\alpha)$} \\
\cline { 2 - 4 } & Beton & $\begin{array}{c}\text { Beton dilapisi } \\
\text { resonator panel } \\
\text { kayu lapis }\end{array}$ & $\begin{array}{c}\text { Beton dilapisi } \\
\text { resonator panel kayu } \\
\text { lapis berlubang }\end{array}$ \\
\hline 500 & $0,17 \pm 0,04$ & $0,23 \pm 0,09$ & $0,32 \pm 0,13$ \\
\hline 1000 & $0,22 \pm 0,04$ & $0,29 \pm 0,05$ & $0,53 \pm 0,10$ \\
\hline 2000 & $0,25 \pm 0,10$ & $0,51 \pm 0,11$ & $0,61 \pm 0,11$ \\
\hline 4000 & $0,11 \pm 0,02$ & $0,27 \pm 0,12$ & $0,41 \pm 0,10$ \\
\hline 8000 & $0,17 \pm 0,02$ & $0,23 \pm 0,06$ & $0,32 \pm 0,14$ \\
\hline
\end{tabular}

Koefisien absorbsi bunyi yang paling tinggi yaitu 0,61 $\pm 0,11$ pada frekuensi $2000 \mathrm{~Hz}$ pada sampel beton dilapisi resonator panel kayu lapis berlubang. Hal ini disebabkan oleh gelombang datang masuk ke lubang kayu lapis dan dipantulkan secara acak di dalam lubang sehingga amplitudo gelombang pantul kecil. Amplitudo gelombang pantul kecil maka amplitudo tekanan minimum menjadi besar. Hasil ini lebih tinggi dibandingkan dengan penelitian sebelumnya panel kayu lapis (plywood) tanpa pori yang dilapisi pada dinding yaitu 0,45 pada frekuensi $100 \mathrm{~Hz}$ (Doelle,1986).

Koefisien absorbsi bunyi paling rendah yaitu $0,11 \pm 0,02$ pada frekuensi $4000 \mathrm{~Hz}$ diperlihatkan oleh sampel beton. Hal ini disebabkan oleh beton lebih pejal dibandingkan dengan kayu lapis. Gelombang datang kesulitan memasuki beton karena lebih pejal sehingga bunyi lebih banyak dipantulkan. Amplitudo gelombang pantul pada beton lebih besar dibandingkan amplitudo gelombang pantul pada permukaan panel kayu lapis berlubang. Hal ini diperlihatkan oleh amplitudo tekanan minimum yang kecil.

Hubungan antara nilai koefisien absorbsi bunyi dengan frekuensi diperlihatkan pada Gambar 2. 


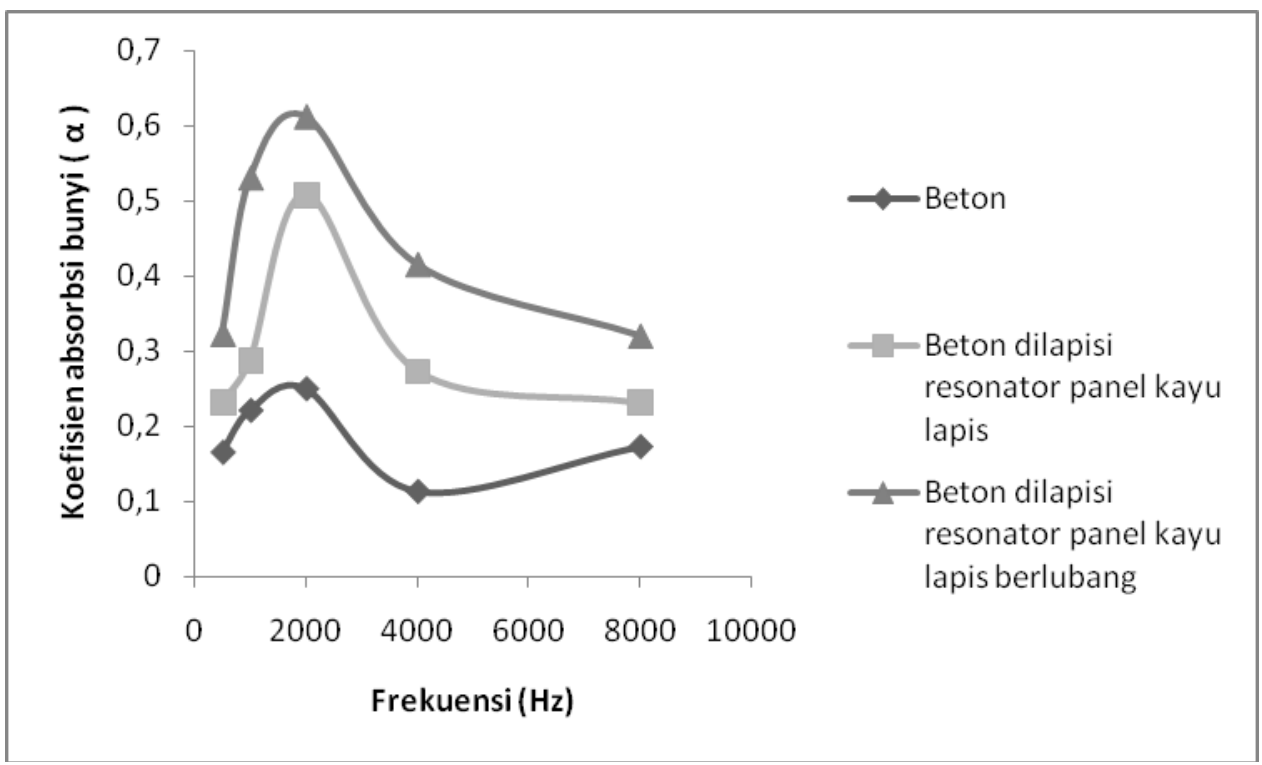

Gambar 2. Hubungan koefisien absorbsi ( $\alpha$ ) pada beton, beton dilapisi resonator panel kayu lapis dan beton dilapisi resonator panel kayu lapis berlubang terhadap frekuensi

Gambar 2 memperlihatkan koefisien absorbsi bunyi beton dilapisi resonator panel kayu lapis berlubang lebih tinggi dibandingkan dengan resonator panel kayu lapis dan beton saja pada frekuensi $500 \mathrm{~Hz}$ sampai dengan $8000 \mathrm{~Hz}$. Bunyi yang diserap oleh beton dilapisi resonator panel kayu lapis berlubang sebesar $61 \%$ dan bunyi yang dipantulkan sebesar 39\%. Hal ini disebabkan oleh gelombang datang masuk ke lubang dan terjadi resonansi akibatnya gelombang pantul menjadi lemah. Melemahnya amplitudo gelombang pantul diperlihatkan oleh amplitudo tekanan minimumnya yang besar.

Koefisien absorbsi bunyi pada beton dilapisi resonator panel kayu lapis berlubang meningkat dari frekuensi $500 \mathrm{~Hz}$ hingga frekuensi $2000 \mathrm{~Hz}$. Hal ini disebabkan gelombang bunyi masuk ke dalam lubang terjadi pantulan secara acak sehingga amplitudo gelombang pantul melemah, maka amplitudo tekanan minimumnya meningkat, sehingga bunyi yang dipantulkan lebih banyak diserap dari pada dipantulkan.

Koefisien absorbsi bunyi pada beton dilapisi resonator panel kayu lapis berlubang menurun pada frekuensi $4000 \mathrm{~Hz}$ hingga $8000 \mathrm{~Hz}$, hal ini disebabkan amplitudo gelombang pantul meningkat, maka amplitudo tekanan minimumnya melemah, sehingga bunyi yang dipantulkan lebih banyak dipantulkan.

Koefisien absorbsi bunyi beton dilapisi resonator panel kayu lapis lebih besar dibandingkan dengan koefisien absorbsi bunyi beton saja. Koefisien absorbsi bunyi beton dilapisi resonator panel kayu lapis meningkat dari frekuensi $500 \mathrm{~Hz}$ hingga 2000 $\mathrm{Hz}$. Hal ini disebabkan oleh resonator panel kayu lapis lebih berpori dibandingkan dengan beton. Sehingga gelombang datang pada permukaan beton dilapisi resonator panel kayu lapis lebih mudah masuk dibandingkan pada beton, akibatnya amplitudo tekanan minimum beton dilapisi resonator panel kayu lapis lebih tinggi dibandingkan dengan beton saja.

Koefisien absorbsi bunyi beton dilapisi resonator panel kayu lapis menurun pada frekuensi $4000 \mathrm{~Hz}$ hingga $8000 \mathrm{~Hz}$. Hal ini disebabkan amplitudo gelombang pantul meningkat, sehingga gelombang bunyi yang datang melemah, mengakibatkan amplitudo tekanan minimumnya meningkat, mengakibatakan koefisien absorbsi bunyi menurun, sehingga lebih banyak bunyi dipantulkan dari pada yang diserap. 
Koefisien absorbsi bunyi beton paling rendah dibandingkan dengan beton dilapisi resonator panel kayu lapis dan resonator panel kayu lapis berlubang. Bunyi yang diserap oleh beton sebesar $11 \%$ dan yang dipantulkan sebesar $89 \%$. Koefisien absorbsi bunyi beton meningkat pada frekuensi $500 \mathrm{~Hz}$ hingga $2000 \mathrm{~Hz} \mathrm{Hal} \mathrm{ini} \mathrm{disebabkan} \mathrm{oleh} \mathrm{material}$ beton lebih pejal dibandingkan dengan kayu lapis dan pori-pori beton lebih kecil dibandingkan dengan pori-pori kayu lapis. Gelombang datang pada beton susah memasuki pori-pori sehingga lebih banyak dipantulkan, mengakibatkan amplitudo tekanan minimum kecil.

Apabila melewati frekuensi optimum yaitu $4000 \mathrm{~Hz}$ maka koefisien absorbsi mengalami penurunan hal ini disebabkan apabila melewati frekuensi optimum maka amplitudo tekanan minimum lebih kecil, kecuali pada frekuensi $8000 \mathrm{~Hz}$ pada sampel beton terjadi kenaikan koefisien absorbsi bunyi hal ini disebabkan amplitudo tekanan minimumnya besar sehingga bunyi lebih banyak diserap.

\subsection{Nilai Impedansi Material Akustik}

Nilai impedansi akustik pada masing-masing material dapat dihitung setelah diperoleh nilai $(S W R)$, jarak minimum pertama $\left(d_{1}\right)$ dan jarak dari minimum pertama ke minimum kedua $\left(d_{2}\right)$ pada material tersebut. Setelah dilakukan pengukuran dan perhitungan maka diperoleh data seperti diperlihatkan pada Tabel 2

Tabel 2 Impedansi akustik pada material beton, beton dilapisi resonator panel kayu lapis dan beton dilapisi resonator panel kayu lapis berlubang

\begin{tabular}{|c|c|c|c|}
\hline \multirow{2}{*}{$\begin{array}{c}\text { Frekuensi } \\
(\mathrm{Hz})\end{array}$} & Beton & $\begin{array}{c}\text { Beton dilapisi } \\
\text { resonator panel } \\
\text { kayu lapis }\end{array}$ & $\begin{array}{c}\text { Beton dilapisi } \\
\text { resonator panel } \\
\text { kayulapis berlubang }\end{array}$ \\
\hline 500 & $0,38-0,56 \mathrm{i}$ & $0,63-0,40 \mathrm{i}$ & $0,83-0,24 \mathrm{i}$ \\
\hline 1000 & $0,37-0,58 \mathrm{i}$ & $0,57-0,42 \mathrm{i}$ & $0,96-0,08 \mathrm{i}$ \\
\hline 2000 & $0,70-0,38 \mathrm{i}$ & $0,90-0,17 \mathrm{i}$ & $0,97-0,05 \mathrm{i}$ \\
\hline 4000 & $0,63-0,42 \mathrm{i}$ & $0,74-0,32 \mathrm{i}$ & $0,89-0,20 \mathrm{i}$ \\
\hline 8000 & $0,87-0,21 \mathrm{i}$ & $0,90-0,18 \mathrm{i}$ & $0,92-0,14 \mathrm{i}$ \\
\hline
\end{tabular}

Berdasarkan Tabel 2 dapat diplot grafik hubungan antara impedansi akustik dengan frekuensi pada beton, beton dilapisi kayu lapis dan beton dilapisi kayu lapis berlubang seperti diperlihatkan pada Gambar 3.

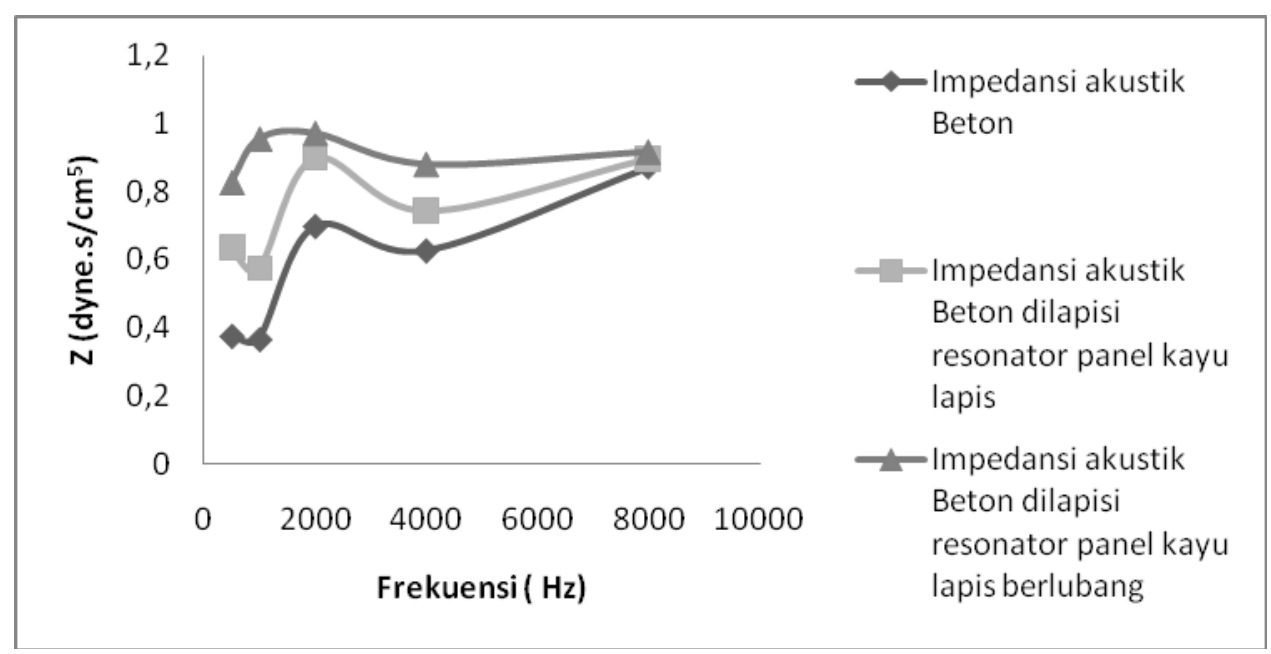

Gambar 3 Hubungan impedansi akustik terhadap frekuensi 
Impedansi akustik beton dilapisi resonator panel kayu lapis berlubang lebih tinggi dibandingkan dengan resonator panel kayu lapis dan beton saja. Hal ini disebabkan oleh hambatannya lebih besar ditunjukan oleh tekanan amplitudo minimum yang tinggi.

Impedansi akustik beton dilapisi resonator panel kayu lapis lebih tinggi dibandingkan beton saja. Hal ini disebabkan oleh beton dilapisi resonator panel kayu lapis hambatannya lebih besar yang ditunjukan oleh tekanan amplitudo minimum yang tinggi. Beton memiliki impedansi akustik paling rendah disebabkan oleh hambatan rendah karena beton lebih pejal. Hal ini diperlihatkan oleh amplitudo tekanan minimum yang rendah.

Impedansi akustik paling tinggi yaitu 0,97-i0,05 pada frekuensi $2000 \mathrm{~Hz}$ pada sampel beton dilapisi resonator panel kayu lapis berlubang. Impedansi akustik paling rendah yaitu $0,37-i 0,58$ pada frekuensi $1000 \mathrm{~Hz}$ pada beton. Hal ini disebabkan oleh hambatan pada beton lebih kecil yang diperlihatkan oleh tekanan amplitudo minimumnya yang kecil.

\section{KESIMPULAN}

Beton yang dilapisi resonator panel kayu lapis berlubang memilki nilai koefisien absorbsi bunyi paling tinggi yaitu $0,61 \pm 0,11$ pada frekuensi $2000 \mathrm{~Hz}$ dibandingkan dengan beton yang dilapisi kayu lapis dan beton saja. Penambahan resonator panel kayu lapis berlubang pada permukaan beton dapat meningkatkan koefisien absorbsi bunyi dari $11 \%$ bunyi yang diserap menjadi $61 \%$ bunyi yang diserap. Nilai impedansi akustik paling tinggi 0,97-i0,05 pada frekuensi $2000 \mathrm{~Hz}$.

\section{UCAPAN TERIMA KASIH}

Terimakasih kepada Fakultas Matematika dan Ilmu Pengetahuan Alam atas dana hibah penelitian dosen muda dan mandiri tahun 2015.

\section{DAFTAR PUSTAKA}

1. Beranek, L., 1949, Acoustic Measurement, John Wiley \& Sons Inc., New York.

2. Doelle, E., 1986, Akustik Lingkungan, Erlangga, Jakarta.

3. Gurning, N., 2013, Pembuatan Beton Serat Tandan Kosong Kelapa Sawit, Jurnal Ilmu Pengetahuan dan Teknologi, Vol.31, No.1, Jur. Fisika Universitas Sumatera Utara.

4. Lewis, H. dan Douglas, H., 1993, Industrial Noise Control Fundamentals and Application, Reyised, New York.

5. Oktaviani, A., 2013, Pengaruh Celah Permukaan Bahan Kayu Lapis (Plywood) Terhadap Koefisien Absorbsi Bunyi dan Impedansi Akustik, Skripsi, Unand, Padang.

6. Sutrisno., 1979, Fisika Dasar, Institut Teknologi Bandung, Bandung.

7. Tipler, P., 1991, Fisika Untuk Sains dan Teknik, Jilid 1, Edisi Ketiga, Erlangga, Jakarta. 